\title{
El mito de la autoridad: entre deconstrucción y psicoanálisis
}

\author{
Javier Agüero Águila'
}

Recibido: 11 de abril de 2019 - Aceptado: 2 de junio de 2019

\begin{abstract}
Resumen
El presente texto pretende establecer una relación entre el mito y la autoridad a partir de claves de lectura extraídas de la deconstrucción derridiana y el psicoanálisis de Freud y Lacan. En esta perspectiva se entenderá, primero, que no es posible ingresar al pensamiento de Freud sin examinar obligadamente la noción de "mito" y la mitología en general. En segundo lugar, se analizará la noción de "mitología blanca" en Jacques Derrida, como un espacio al interior del cual los mitos parecen diseminarse. En un tercer momento se analizará la idea de autoridad en los relatos freudiano y lacaniano, intentando dar cuenta del tratamiento fundamentalmente "familiar" que adquiere esta cuestión en el psicoanálisis. Finalmente, se apostará por una lectura de Derrida en la que la autoridad podría ser comprendida como una suerte de Khôra, es decir, como un tercer género que desactiva la oposición mito-logos.
\end{abstract}

Palabras clave: mito - autoridad - Freud - Derrida - Lacan

\section{The myth of authority: between deconstruction and psychoanalysis}

\section{Summary}

This text sets out to establish a relationship between myth and authority, based on readings extracted from Derridean deconstruction and the psychoanalysis of Freud and Lacan. In this perspective it shall be understood that first of all, it is not possible to access the thinking

1 Chileno, Licenciado en Sociología y Sociólogo por la Universidad Academia de Humanismo Cristiano, Chile; Magíster en Filosofía Política por la Universidad de Chile; Doctor en Filosofía por la Universidad París 8 Vincennes/Saint-Denis, Francia. Director del Centro de Investigación en Religión y Sociedad (CIRS) de la Universidad Católica del Maule y académico del Departamento de Filosofía de la misma institución. Contacto: jaguero@ucm.cl

ORCID: https://orcid.org/0000-0001-8990-9613 
of Freud without necessarily having examined the notion of "myth" and mythology in general. We go on to analyze the notion of "white mythology" in Jacques Derrida, as a space within which myths appear to be disseminated. The third strand of the article addresses the idea of authority in the works of Freud and Lacan, in a bid to examine the fundamentally "family" type of treatment that this issue acquires in psychoanalysis. Finally, we turn attention to a reading of Derrida in which authority may be understood as a form of Khôra, a third gender that deactivates mythological opposition.

Keywords: myth - authority - Freud - Derrida - Lacan

\section{0 mito da autoridade: entre desconstrução e psicanálise}

\section{Resumo}

O presente texto pretende estabelecer uma relação entre o mito e a autoridade a partir de chaves de leitura extraídas da desconstrução derridiana e da psicanálise de Freud e Lacan. Nesta perspectiva se entenderá, primeiro, que não é possível entrar no pensamento de Freud sem examinar obrigatoriamente a noção do "mito" e da mitologia em geral. Em segundo lugar, será analisada a noção de "mitologia branca" em Jacques Derrida, como um espaço no interior do qual os mitos parecem se disseminar. Em um terceiro momento se analisará a ideia de autoridade nos relatos freudiano e lacaniano, apresentar o tratamento fundamentalmente "familiar" que esta questão adquire na psicanálise. Finalmente, se apostará por uma leitura de Derrida na qual a autoridade poderia ser compreendida como uma espécie de Khôra, ou seja, como um terceiro gênero que desativa a oposição mito-logos.

Palavras-chave: mito - autoridade - Freud - Derrida - Lacan

\section{Introducción}

La civilización es algo impuesto a una mayoría recalcitrante por una minoría que ha sabido apropiarse de los medios de poder y de compulsión.

S. Freud

Hay dos palabras que están implicadas, en principio, en el título en este texto. Se habla de "mito" y de "autoridad". Más aún, insistimos en conectar estas dos palabras a través de un "de" (el mito de la auto- 
ridad) que indica una pertenencia, una correspondencia de posesión o de imbricación entre el mito y la autoridad mismos. Hablamos del mito de la autoridad como si a la autoridad le fuera su propio mito, o como si el mito tuviera, entre sus posibilidades, una responsabilidad fundante o explicativa con la autoridad propiamente tal.

Al mismo tiempo, el título expresa una relación, un entre, que liga a dos tradiciones que parecen mimetizarse en un vínculo hereditario ${ }^{2}$ : nos referimos a la deconstrucción y al psicoanálisis, y nos hacemos, a modo general, las siguientes preguntas: ¿cuál es el estatuto de la relación entre deconstrucción y psicoanálisis? ¿Es Derrida un heredero de Freud? O, de otra manera, ¿es la deconstrucción una heredera del psicoanálisis? Es decir, ¿de aquello que supera a los nombres propios —Derrida/Freud—, transformándolos en su obra?, esto es, ¿en aquello que ya no les pertenece? De esta manera, René Major escribirá que "El psicoanálisis es de lo que Derrida no se olvida nunca. Él tiene con el psicoanálisis un lazo imaginario como con su lengua materna" (2001 5 traducción mía).

Para este texto, será importante insistir en este entre a través de las nociones de "mito" y "autoridad", trayendo a escena, también, aquello que el psicoanálisis lacaniano puede decir en esta ruta.

En esta dirección e inicialmente, lo que parece estar en juego cuando hablamos de mito es la idea misma de "verdad". Podríamos decir, junto a Gilles Deleuze, en esta dirección, que "[...] si alguien quiere la verdad no es en nombre de lo que es el mundo, sino en nombre de lo que el mundo no es" (2006 136). Entonces, el mundo de las cosas

2 Para profundizar en la herencia freudiana en el trabajo de Derrida, se sugiere el texto de Javier Agüero Águila A pesar de la herencia. Sobre lo pendiente entre Freud y Derrida: "Derrida asume al psicoanálisis como ninguna otra cosa más que como un acontecimiento, es decir, como un evento que concurre desde un devenir noplanificado y altamente corrosivo para una suerte de historia lineal de la filosofía. Este acontecimiento, que amenazó de tal manera la secuencialidad del pensamiento filosófico al punto de casi desbordarlo, se habría visto expuesto a esta especie de restauración vergonzosa y deshonesta de la filosofía y su secuencia, en donde cualquier apuesta por descentrar el pensamiento racional debía ser descartada, metida en un cajón de sastre y olvidar entonces la fuerza hereditaria que la constituye" (2014 68). 
tangibles, de lo "real", pareciera no ser el lugar en que habita la verdad —si seguimos a Deleuze-, sino que sería necesario buscarla fuera de la materialidad, en un no-lugar que se desliga del mundo categorizable. Si hay verdad, si existe algo así como la verdad de cualquier cosa, ésta se intuye fuera del alcance de la razón. Es entonces que la idea de "mito" podría cobrar importancia: si la autoridad tiene un mito, si hay un no-logos deambulando como sustancialidad in-aparente en la autoridad misma, entonces, y en un sentido deleuziano, ésta tendría una verdad (aunque esté fuera del mundo).

Si despejamos la etimología de la palabra "mito", nos daremos cuenta de que ésta no es tan clara, precisamente porque su raíz no se encuentra en otras lenguas indoeuropeas. Podríamos aventurar y decir que la propia etimología de la palabra "mito" es un mito; un tipo de palabra que revela, por su propia ausencia de origen etimológico, su significado más explícito. Sin embargo, siguiendo algunos diccionarios de etimología, entendemos que el nombre está formado a partir de la palabra griega $\mu \nu \theta 0 \varsigma$ (mythos), que quiere decir "cuento o relato; palabra no racional; después discurso; después ficción, que ha pasado al latín como 'mythos': fábula"3. Sin embargo y más allá de estas formas, la palabra parece siempre haber indicado ausencia de razón y primacía de lo ficcional. Si tenemos alguna posible certeza en relación al mito, ésta radica en su temprano parentesco con la ficción. Platón, por ejemplo, indicaba al mito (mythoi) como aquello "que pretende encubrir alegóricamente verdades que están más allá de lo comprobable mediante el logos". Hablamos de un mito como encubridor de lo real; el mito mitómano o el mito sin logos que se desmarca de lo tangible y corona a la ficción. Por otro lado, ya en La Poética, Aristóteles señalaba que "el mito es el principio y como el alma de la tragedia" (Poét. 1450a 22-23). O, cuatros siglos antes,

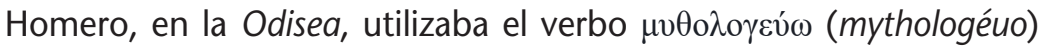
en el sentido de contar un relato y se preguntaba "¿qué más he de contar"? (Canto XII vv. 447).

${ }_{3}^{3}$ Consultado en: http://lettres.tice.ac-orleans-tours.fr/php5/coin_eleve/etymon/ etymonlettres/narration/mythe.htm 
Sabemos que la tragedia griega es uno de los espacios principales para la emergencia de la hipérbole, de la exageración de lo real, y es aquí precisamente donde el mito se disemina como válvula explicativa y corazón de la idealidad helénica. Sin embargo, nuestro objetivo es repensar al mito como fundamento de la autoridad desde una lectura contemporánea, derivada, por un lado, del pensamiento de la deconstrucción y, por otro, del tratamiento que tiene esta cuestión en el psicoanálisis. Esta es nuestra elección.

Con todo, el mito como disposición a la verdad racional es un problema; su lugar, si lo tiene, es el de una cierta vecindad con lo inmaterial, con lo alegórico y con una forma particular de irracionalidad.

Consideramos necesario, impulsados por la arbitrariedad de la elección, seguir despejando la idea de "mito". Este "despejar" pretende, en el sentido de búsqueda —al menos—, insinuar a este mito (inubicable en el mundo del logos) como "otra razón" de la autoridad.

\section{Freud y su pulsión al mito}

Una ruta primera, al momento de pensar al mito y la autoridad, se evidencia en las lecturas de Freud. En Tótem y Tabú, por ejemplo, Freud se arriesga con la invención de una primera forma social reglamentada que definió como "horda primitiva". Influenciado probablemente por el darwinismo, Freud intuye que esta formación sucede a la natural y se establece como fundamento de lo que posteriormente denominaremos "cultura". Lo que nos importa en este trabajo no es la conceptualización de esta formación social, sino más bien la necesidad freudiana de recurrir a una ficción (mito), de la cual, por cierto, él no podía dar ninguna certeza empírica de su existencia ${ }^{4}$. Él mismo define a esta formación primitiva como una "hipótesis conjetural" (Freud 1988).

4 En la línea de la conjetura freudiana y de sus permanentes excesos especulativos, resulta interesante dar cuenta de que Derrida llama a Freud "el especulador". Derrida se está refiriendo, particularmente, a la teoría del Fort-da freudiana. Freud habría levantado su teoría sobre el Fort-da ("lejos" en alemán) sobre la base del examen de las actitudes de un niño de 18 meses (su nieto), no solo para dar cuenta de cómo 
Recordemos que el mito de la horda primitiva intenta explicar cómo el pasaje de la naturaleza a la cultura está definido por el parricidio. En otras palabras, la monopolización de la violencia y el placer por parte del padre, azuzó la rebelión de los hijos que, asesinándolo, desplazaron al hombre de un estado natural a uno de mayor complejidad asociativa. Nuestros complejos, remordimientos y prescripciones experimentados en el mundo de la cultura vendrían, entonces, de ese crimen original que organiza la vida social.

Si nos detenemos ahora en Edipo, otro de los mitos célebres de los cuales se sirve Freud para crear esta suerte de antropología psíquica del hombre moderno que es el psicoanálisis, veremos cómo los personajes de la tragedia de Sófocles adquieren en Freud características que originalmente no tenían, pero que, sin embargo, le rinden para explicar especulativamente el origen de la neurosis contemporánea. Es cierto que Edipo es, en la tragedia de Sófocles, el asesino de su padre (Layo) y el esposo de su madre (Yocasta); sin embargo, él no sabía conscientemente que mataba a su padre ni tampoco que la mujer a quien deseaba era su madre. Esta es la verdadera tragedia; la que se construye desde el no saber lo que se hace, desde el error involuntario. Aquí no se despliegan deseos ni pulsiones de muerte de ningún tipo. Freud reinventa el mito (quizás inspirado por los

operaba el principio del placer, sino que, y en gran medida, para explicarse cómo la constitución del lenguaje pasa por una experiencia de la pérdida. En esta línea, el Fort-da es una experiencia específica y total a la vez, en la que se juega la constitución del sujeto. Sin embargo, y más allá de la particular vivencia del niño, que arroja un objeto para después recuperarlo, asumiendo inconscientemente que es la figura de su propia madre la que está y no está, Derrida ve en esta escena un gesto freudiano de un enorme impacto, preguntándose cómo es posible que Freud haya podido lograr toda una obra, una escena de escritura, especulando sobre la experiencia de un niño que, además, era su nieto, es decir, sobre el cual no podía aplicar ningún tipo de objetividad. El desplazamiento desde un momento de observación especulativa hacia el del levantamiento de una teoría acerca de un Más allá del principio del placer, le parece a Derrida profundamente significativo. "[...] se trataba de interrogar a la especificidad (problemática y textual) del Más allá..., de ligar lo irreductible de una «especulación» con la economía de una escena de escritura, inseparable a su vez de una escena de herencia, que implica a la vez a Freud y al «movimiento psicoanalítico»" (Derrida 1980 393-412 traducción mía). 
descubrimientos de fines del siglo XIX y principios del XX, de ruinas tales como Micenas o Troya) y altera la tragedia en función de sus propios objetivos, atribuyéndole a Edipo la carga de ser culpable de un doble deseo, el de matar a su padre y el de poseer sexualmente a su madre.

Freud, en su (com)pulsión mitológica, no deja de corromper a los mitos mismos, haciéndolos rendir en el plano de una supuesta rigurosidad científica (reconocida es también su compulsión empírica, que implicaba el análisis de un gran número de casos — pacientes_ - antes de elaborar un texto que expusiera sus conclusiones). Lo importante, insistimos, es dar cuenta de cómo la narración de ficciones fundamentales representa para Freud una inestimable fuente de riquezas especulativas sobre las cuales va formando y dándole el tono al psicoanálisis. La búsqueda meticulosa al interior de la mitología griega —y también shakesperiana — no es una pura dimensión auxiliar en su aventura por conocer el funcionamiento del inconsciente, sino, más bien, un esfuerzo interpretativo colosal que busca en los mitos del pasado los elementos para una formulación de la psiquis moderna. Para Freud, los mitos conservan de manera amorfa y desfigurada, en sueños y lapsus, ciertos hitos de la humanidad, y dan cuenta de forma inconsciente de hechos capitales en la historia. Solo accediendo al mito, pariente cercano de la ficción, pudo Freud levantar un sistema de interpretación sobre los padecimientos concretos de la psiquis humana. En esta misma línea, Freud escribe en una carta enviada a Wilhelm Fliess en diciembre de 1888:

¿Puedes imaginarte lo que son mitos endopsíquicos? El más reciente engendro de mi trabajo mental. La oscura percepción interna del propio aparato psíquico incita a ilusiones cognitivas que naturalmente son proyectadas hacia fuera y, de manera característica, al futuro y a un más allá. La inmortalidad recompensa, todo el más allá son tales figuraciones de nuestro interior psíquico. ¿Chifladuras? ¿Psicomitología? (Freud 1994 311). 
Podemos leer en esta cita, que Freud intenta desplazar al mito en su versión de relato ficcional a una zona de comprensión primigenia del aparato psíquico. El mito se condensaría en un lugar oscuro y difuso de la psiquis humana — que bien podríamos llamar inconsciente-, desde el cual presiona por emerger a la cultura, caracterizando nuestra estructura cognitiva y proponiendo un nuevo modelo de comprensión de fenómenos tales como, por ejemplo, la represión. Hay represión porque no se identifica lo traumático, lo cual, en este caso, tendría una determinación mitológica altamente indescifrable e irreductible a lo simbólico, pero que, no obstante, se adhiere como un barniz a la estructura formal de las implicaciones culturales. El punto es que no sabemos de dónde obtiene el mito esta capacidad de adherencia, precisamente, porque no sabemos dónde está ni cómo se disemina en la experiencia fenomenal de los individuos.

Por otro lado, Freud mismo se refiere a la especulación mitológica que está llevando a cabo como "chifladuras". La palabra no es menor, viniendo de un miembro del Círculo de Viena, cuya tarea más temprana fue la de intentar encontrarle al inconsciente un registro anatómico, es decir, un lugar físico dentro del cerebro. Tal es el Freud neurólogo, positivista y de una fuerte impronta empírica. "Chifladuras", tal como lo señala, es una palabra que nos deriva hacia un cierto desvarío y a un desvío en su búsqueda de leyes que permitan estructurar el funcionamiento del inconsciente. Hay, en esta palabra, una fuga hacia una zona irracional, descuidada y desprovista de método que solo puede, así como Freud mismo lo remarca, disponerse como un mito. ¿Cuán importante es la dimensión mitológica en la organización de todo el pensamiento psicoanalítico? Más allá de los detractores, el psicoanálisis es un canon indescartable de la modernidad inspirado en claves mitológicas. 


\section{Jacques Derrida y la "blancura" del mito}

Los mitos tienen más poder que la realidad. La revolución como mito es la revolución definitiva.

Camus

Tomando ahora la ruta derridiana, vemos que, en la Mythologie blanche, Derrida pareciera hacer equivalente el mito a la metáfora. Habría, para él, una usura de la metáfora por parte del lenguaje filosófico que se representa en la filosofía misma (un autoritarismo). No obstante, todo vendría de la metáfora. En la articulación del lenguaje habría una capitalización de la metáfora más no la metáfora misma: "La palabra no es pronunciada, sin embargo, podemos descifrar el doble alcance de la usura: el borramiento por fricción, el agotamiento, la erosión, cierto, pero también el producto suplementario de un capital" (Derrida 1972 250 traducción mía). La metáfora es utilizada y, a partir de la usura, es transformada en suplemento de sí misma para efectos del lenguaje. ¿Esta definición no es, acaso, una aproximación al mito? ¿Mito como metáfora que nutre con sus suplementos al mundo real? ¿No es el mito una metáfora original que preña e inyecta de sentido a la praxis de la cultura? Y, entonces, ¿es un gesto autoritario?

Ahora bien, es importante señalar que, para Derrida, todo tiene un tránsito a través de la metáfora. No habría, en esta línea, espacio para la formulación conceptual de lo que sea, en cualquier formato lingüístico, sin el desplazamiento por la metáfora. En esta dirección "[...] no hay nada que pase sin la metáfora y por la metáfora. Todo enunciado en relación al tema que sea que ocurra no puede ser producido sin metáfora" (Derrida 1987a 65 traducción mía). Entonces, la metáfora es, en esta perspectiva, dilación y contexto, espaciamiento y cuerpo, différance ${ }^{5}$ adherida a cualquier manifes-

\footnotetext{
5 Aunque la noción de différance no se desarrolle en profundidad en este texto, es necesario destacar, a modo general, lo que Derrida sugiere al respecto. Él entiende la différance como la economía más fundamental en el seno de la cual todo sentido emerge y se disemina (antagonismos conceptuales y posibilidades del lenguaje). No habría, en esta dirección, différance de la différance, siendo la différance causa de sí misma (Derrida 1968).
} 
tación expresada sobre cualquier cosa. La Katastrophé, que indica Derrida en el texto La retrait de la métaphore, no sería más que la retirada de la metáfora de toda formación de sentido y, entonces, la ruina de la representación. En otras palabras, hay Katastrophé cuando se prescinde de la metáfora; cuando ha sido tal el nivel de usura que ésta terminar por evaporarse o desvanecerse en su estancamiento logocéntrico. Entonces, el sentido no es más que un puro sentido sin metáfora adherida; una única manifestación del logos que logró independizarse de la metáfora, estableciendo, en adelante, una condición iterable ${ }^{6}$ alejada de cualquier formación, digamos, espiritual (mito).

[...] lo hago para remarcar con un trazo suplementario que, para mí, no se trata solo de tener en consideración las proposiciones enunciadas, los temas y las tesis a propósito de la metáfora en cuanto tal, el contenido de su discurso, que trata de la retórica y de este tropo, sino más bien de su escritura, de su tratamiento de la lengua y, más precisamente, de su tratamiento del trazo, del trazo en todos los sentidos: más precisamente todavía, del trazo como palabra de su lengua, del trazo como encentadura que rasga la lengua (Id. 67 traducción mía).

Insistimos en que la metáfora, aquí, puede ser entendida como la adherencia mitológica a cualquier manifestación de sentido —lingüístico o no- que pretenda algún tipo de exterioridad. La metáfora bien podría ser la formulación ficcional e inubicable de una fuerza mitológica que se expande en una tierra deshabitada y radicalmente a-logos, pero que, sin embargo, es el paso exigido para cualquier manifestación logocéntrica en esta línea.

Pero volvamos al punto anterior, al de la usura de la metáfora. En el transcurso de la apropiación de la metáfora se van produciendo

6 Como lo sostiene Cristina de Peretti: "[...] la iterabilidad, mezcla de repetición y de différance, es siempre diferente; por eso, tiene lugar cada vez como única vez" (2005 126). 
borraduras, prótesis de origen (Derrida 1997), que tienden a superar lo mitológico de la metáfora. Por "prótesis de origen" cabe entender aquella expresión de sentido típica del logos que se produce, reproduce, repite e itera como ficción del origen. En toda enunciación que persiga establecer un sentido, ya sea lingüístico o de cualquier orden, lo que se despliega es una empresa totalizadora que instala a este sentido en un presente, en un aquí y ahora que desestima radicalmente ese origen difuso y sin ubicación posible que podríamos denominar "différance" (o mito según nuestro interés en este trabajo). Sin embargo, la riqueza primitiva del mito metafórico es una economía irreductible, un terreno de in-apropiación que siempre quedará como resto o huella de sentido primero.

Este sentido primero, no obstante, y como lo sostiene Derrida, no es propiamente una metáfora, sino una región transparente, blanca, en donde se juega la posibilidad de la metáfora misma y su posterior usura por parte del lenguaje. Siempre podríamos volver a esta región blanca en la cual los sentidos primeros y últimos se juegan rizomáticamente $^{7}$. Derrida escribe: "Aunque la metáfora metafísica haya puesto todo sentido arriba o abajo, aunque haya también borrado pilas de discursos, deberíamos siempre poder reactivar la inscripción primitiva y restaurar el palimpsesto" (Derrida 1972250 traducción mía). Palimpsesto: papel en donde una escritura fue borrada para escribir, sobre ella, otra. Sin embargo, siempre se traslucen los signos de la inscripción primera. El logos en esta perspectiva no puede borrar el mito, sino que, únicamente, reescribir "sobre" él. Más aún, no puede borrar la caligrafía fantasmal que para siempre se intuye en ese más allá del mito que es la región blanca derridiana. Todo lo que se escriba "sobre" el mito o la blancura del mito, es desde ya una reinscripción, una prótesis

\footnotetext{
7 Si arriesgamos, la mitología blanca se desplegaría —o, más bien, se diseminaríacomo condición pre-ontológica para la ontología del ser mismo y, con esto, Derrida apuntaría a una nueva estrategia filosófica de superación del dasein heideggeriano, o de la metafísica de la presencia en general. No profundizaremos este problema en este artículo, pero es válido intuir a la mitología blanca como una de las "fórmulas" derridianas dirigidas a desestabilizar la problemática del ser, de la presencia y de la temporalidad en Heidegger (Derrida 1972b).
} 
que no engendra sentido, sino que, más bien, lo plagia y se alimenta de su origen sin origen, de su condición infinitamente inubicable y radicalmente irreductible.

\section{La familia y la autoridad}

Sería necesario, a esta altura y para conservar una suerte de linealidad, poder dirigirnos a la autoridad y comenzar por volver a Freud, como si fuera casi una necesidad; desconcertante necesidad que inscribe a Freud mismo, primero, como un mito al que se vuelve $y$, segundo, como una autoridad a la que se debiera escuchar, aunque intentemos liberarnos de sus indicaciones.

Como sostiene Freud en La novela familiar de los neuróticos, los individuos, en la medida que crecen, dejan de ver a los padres como la gran autoridad. Esto es un proceso doloroso y que genera perplejidad; sin embargo, Freud asume que esta progresiva desafiliación es un imperativo para que la sociedad progrese. El hijo desestima al padre y cuestiona su autoridad, así como la hija hace lo mismo con su madre, escondiéndose tras esta operación una profunda rivalidad sexual que da sentido a la novela. Freud dice:

Ahora bien, aquí se muestra ya la influencia del sexo, pues el varoncito presenta inclinación a mociones hostiles mucho más hacia su padre que hacia su madre, y se inclina con mayor intensidad a emanciparse de aquel que de ésta. Puede ocurrir que la actividad fantaseadora de la niña pequeña resulte harto más débil en este punto. En tales mociones conscientemente recordadas de la infancia hallamos el factor que nos posibilita entender el mito (1908 218, cursivas mías).

Los hijos buscan en otros padres características que en los propios no encuentran, atribuyéndoles a sus progenitores debilidades y haciendo gloriosas a figuras paternales externas. No obstante:

[...] en efecto, si uno escruta en los detalles, las más frecuentes de esas fantasías noveladas, esa sustitución de 
ambos progenitores o del padre solo por unas personas más grandiosas, descubre que estos nuevos y más nobles padres están íntegramente dotados con rasgos que provienen de recuerdos reales de los padres inferiores verdaderos, de suerte que el niño en verdad no elimina al padre, sino que lo enaltece (Id. 220).

Lo cierto aquí es que jamás se renegó de la autoridad paternal, sino que el niño se generó un relato psíquico de una edad de oro en que los padres eran el principio y el fin de toda autoridad posible $y$, aunque parecieran querer borrar su figura, lo cierto es que los niegan para recuperarlos aún más grandes y con una autoridad reforzada. Es el eterno retorno a la horda primitiva y al mito del parricidio como fundación de la cultura.

La autoridad, podemos decir en este punto, no desapareció, sino que entró en una suerte de crisis. La autoridad se retira para volverse aún más determinante. ¿No es acaso éste el eterno movimiento de una autoridad mitológica que tiende a postergarse para reaparecer nuevamente con toda la fuerza de su ficción? ¿No hay, siguiendo el hilo del relato freudiano, una inmanencia mitómana en toda crisis de la autoridad? O, dicho de otra forma, ¿no es acaso cuando menos creemos en la autoridad, cuando la definimos en crisis, que su fuerza fundante se hace más presente?

Lacan, por su parte, en el seminario IV titulado La relation d'objet (1994), estima que la figura paternal es decisiva en la construcción del sujeto. El niño es aquel que no habla y, precisamente por su encuentro con el padre y su edificación autoritaria, puede pasar por la experiencia del lenguaje y transformarse en sujeto. Así, Para Lacan es posible hablar, primero, de una paternidad imaginaria que habita, necesariamente, en el registro de lo imaginario. Este registro es el de la autentificación del yo por contrastación, es decir, me relaciono con otro que me conforma en un plano de dialéctica elemental. Este padre imaginario se revela en la vida del niño como un organizador del caos y como quien configura el orden de las cosas. Es un dios creador. "El padre imaginario es el padre todopoderoso, el fundamento del orden 
del mundo, de la concepción, así como de dios, la garantía del orden universal en sus elementos reales más masivos y más brutales, es aquel que ha creado todo" (Id. 8 traducción mía).

Sin embargo, Lacan desestima la potencia autoritaria del padre imaginario cuando lo contrasta con el padre real. En el seminario Les formations de l'inconscient, Lacan entiende que la autoridad de la figura paterna es poderosa, no solo porque ella reinstala permanentemente al mito de la horda primitiva freudiana, sino también porque, a través de ella, se revela la prohibición del incesto con la madre. De esta manera, Lacan propone una lectura en la cual la autoridad adquiere relevancia en tanto evidencia un trauma y una pulsión espectral que amenaza la dinámica de la cultura: el incesto. Esta triangulación permite a Lacan repensar la autoridad más allá del mito freudiano de la horda primitiva. Vemos que es la figura de la madre la que desplaza en el niño la instalación de una prohibición. Esta prohibición viene del padre simbólico, del nombre del padre, pero se experimenta como un trauma de insatisfacción y represión por parte del hijo.

Al principio mencioné: el padre terrible. De cualquier manera, la imagen resume algo mucho más complejo. Como el nombre lo indica. El padre interviene sobre muchos planos. Primero, prohíbe a la madre. Este es el fundamento, el principio del complejo de Edipo, es aquí que el padre está ligado a la ley primordial, la ley de la prohibición del incesto. Es el padre, se nos recuerda, quien está encargado de representar esta prohibición. A veces tiene que manifestarla de manera directa, por ejemplo, si el niño se entrega a sus expansiones, manifestaciones, inclinaciones. Pero es mucho más allá que el padre ejerce este rol: es por su presencia entera, por sus efectos en el inconsciente que ejerce esta prohibición de la madre (Lacan 1957-1958 105 traducción mía).

Ahora bien, podríamos decir que, en todos estos desplazamientos, se insinúa un retorno a inscripciones más primitivas. En el psicoanálisis estas inscripciones pueden llamarse "pulsiones", es decir, 
escrituras en el inconsciente. La autoridad, en esta línea, sería siempre expresión de inscripciones psíquicas arcaicas —entendemos la palabra "arcaico" desde su etimología original: del griego antiguo

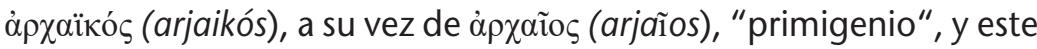
de à $\propto \eta \dot{~(a r j e ́), ~ " p r i n c i p i o ", ~ a ~ s u ~ v e z ~ d e ~ o ́ p \chi \omega ~(a ́ r j o), ~ " c o m e n z a r " — ~} 8$ que tienden a determinar lo que entendemos por "cultura". La prohibición del incesto que expresa la figura materna en el hijo, ¿no es acaso, y a su modo, un tabú mitológico que pretende ordenar el mundo simbólico? ¿No es la autoridad, en su origen, un trauma no simbolizable que espectralmente define las prescripciones de la cultura? Si esto es así, ¿existiría otra forma de entender la autoridad que no sea lanzándose al centro del mito?

Lacan mismo señala, en esta perspectiva, que cuando los límites de la episteme se expresan con claridad y, entonces, cuando ya no nos es posible, mediante una palabra y sus potenciales significantes, atrapar un sentido figurado o explícito, resulta cuando menos urgente referirse al mito. Hacemos venir aquí la palaba "urgente", no en una lógica de la inmediatez, sino en una de la urgencia vital que implica, de alguna u otra forma, intuir la mitología ahí donde el mundo empírico ha instalado sus leyes. Volver al mito de la palabra: aquel que autoriza todo sentido, que ejerce autoridad sobre todos los sentidos posibles y que, precisamente, es más luminoso cuando se pretende más ausente:

Nos resulta perfectamente concebible que haya un límite en el plano del saber, si es cierto que éste es únicamente lo accesible al hacer intervenir de manera pura y simple la ley del significante. En ausencia de conquistas experimentales avanzadas, está claro que en muchos dominios -y en dominios en los que nosotros, por nuestra parte, no lo necesitamos - será urgente dar la palabra al mito (Lacan 19601961 142). 


\section{La autoridad por sí misma}

Quisiéramos reencontrarnos con Derrida. Este reencuentro es necesario para no rehuir las aporías ni los excesos semánticos. Se vuelve también a Derrida como quien vuelve a un fundamento que es, al mismo tiempo, des-fundamento de cualquier autoridad en esta línea.

La autoridad, para Derrida, no puede sino promover una violencia y el ejercicio de una fuerza que se traduce en la vida social. Esta autoridad, sin embargo, no encuentra su origen en ningún otro lugar más que en sí misma. La autoridad es para sí y hacia sí, es decir, su validez no le viene de fundamentos exteriores o seculares. Es entonces que la autoridad se nos revela mística, sin una plataforma a la que podríamos denominar "cultural". Se cree en la autoridad porque es la autoridad, y nada más.

[...] la operación que consiste en fundar, inaugurar, justificar el derecho, hacer la ley, consistiría en un golpe de fuerza, en una violencia que realiza y por tanto interpreta, que no es justa o injusta en sí misma, y que ninguna justicia ni ningún derecho previo y anteriormente fundador, ninguna fundación preexistente, podría garantizar, contradecir o invalidar por definición [...] el discurso encuentra ahí su límite: en sí mismo, en su poder realizativo mismo. Es lo que aquí propongo denominar [...] lo místico. Hay un silencio encerrado en la estructura violenta del acto fundador. He ahí el sentido en el que me atrevería a interpretar, más allá del comentario simplón, lo que Montaigne y Pascal llaman el fundamento místico de la autoridad (Derrida 1994 32-33 traducción mía).

La cita nos señala que lo que entendemos por ley, por norma, prescripción o Derecho a fin de cuentas, no tiene más fundamento que la ausencia de fundamento y que, de esta manera, su legitimidad la encuentra en un espacio altamente heterogéneo e irreductible a codificaciones de orden jurídico, diseminándose más bien en una zona difusa y sin clasificación posible; una mística ilocalizable que, en tanto 
tal y radicalmente fuera de cualquier ley, termina por asumirse como el sentido de la ley y la norma misma.

\section{La autoridad es una especie de Khôra}

El mito pone en juego una forma de lógica que podemos llamar, en contraste con la lógica de la no-contradicción de los filósofos, una lógica de lo ambiguo, de lo equívoco, de la polaridad. ¿Cómo formular, incluso formalizar esas operaciones de báscula que invierten un término en su contrario, manteniéndolas a distancia desde otros puntos de vista?

J-P. Vernant

Para terminar este recorrido — sinóptico— sobre el mito y la autoridad (y la relación complejamente metafísica que parece haber entre ambas nociones), y que nos ha derivado a insistir en ciertos elementos filosóficos propios de la deconstrucción derridiana y el psicoanálisis de Freud y Lacan, quisiéramos referirnos a una última idea de Jacques Derrida. Idea, quizás, de las más radicales trabajadas por este autor, en tanto significa una extensión siempre en desplazamiento hacia zonas ultramitológicas, y en donde todo es, cada vez, aún más irreductible a cualquier categoría, discurso, antagonismo conceptual, en fin, radicalmente heterogéneo a cuál sea la disposición logocéntrica en esta dirección. Nos referimos a la noción de Khôra.

En el texto del mismo nombre, Derrida sostiene que la Khôra (1993), como se expresa en El Timeo de Platón, es algo que se sustrae de lo inteligible. La Khôra, en esta línea, no habita en lo inteligible, pero participa de él de una manera más bien aporética. Si la Khôra se disemina de esta forma en el mundo inteligible no tendría relación ni con lo verdadero ni con lo falso, pero podría ser cualquiera de ellos al mismo tiempo. Sería un "á la fois" inmanente y acechante, que le arrebata al logos sus verdades o falacias pretendidamente inmutables.

¿De qué manera pensar eso que, más allá de la regularidad del logos, su ley, su genealogía natural o legítima, no 
pertenece, sin embargo, strictu sensu, al mythos? ¿Cómo pensar la necesidad de lo que, más allá de la oposición interrumpida o retardada del logos y el mythos, dando lugar a esta oposición y a tantas otras, parece no obstante no someterse a la ley de eso mismo que sitúa? ¿Qué hay de ese lugar? ¿Es nombrable? ¿Y no habría una relación imposible en la posibilidad de nombrar? ¿Existe aquí algo a pensar, como decimos tan rápidamente, y a pensar según la necesidad? (Derrida 199318 traducción mía).

La cita nos lleva a pensar más allá del logos, pero, sobre todo, a intentar superar la dialéctica elemental entre logos y mito. Pareciera que Derrida, en esta dirección, nos indicara que el sentido de lo verdaderamente mitológico no puede ajustarse a las exigencias de este antagonismo. Todo pensar al mito en relación al logos altera y sabotea su potencia que, precisamente, debería ser reinstalada en una zona disociada del logos mismo. Habría entonces, en el mito, una suerte de independencia exagerada (una autoridad descartada pero inherente a la vez); una separación esencial que es inubicable y que nos invita, una vez más y como siempre en el pensamiento de la deconstrucción, a pensar de otra forma, pensar a la vez o de un modo completamente diferente ${ }^{9}$.

Ahora bien, esta suerte de discurso bastardo que es la Khôra, discurso que no engendra al logos y que tampoco proviene de él, ¿no implica, como se pregunta Derrida, al mito? Quisiéramos, en este momento, y contradiciendo arbitrariamente al párrafo anterior, entender al mito como lo que se opone al logos, como su contraparte clásica que desbarata toda posibilidad de atribuirle validez absoluta al pensamiento. Lo decimos así porque la Khôra sería un tercer género, distinto al logos, por cierto, pero también más allá del mito. La Khôra, bajo esta fórmula, es un desvío que deriva hacia espacios aún más primigenios que la formulación de mitos constituyentes. Quizás si, en este punto, y toda

9 Derrida sobre la deconstrucción: "si yo tuviera que arriesgar, dios me guarde de esto, una sola definición de la deconstrucción, breve, elíptica, económica como una palabra de orden, diría sin frase: 'más de una lengua'"' (Derrida 198838 trad. mía). 
vez que hablamos de la Khôra, deberíamos hablar de misticismo, lo que es simplemente porque es, sin más razón aparente que su símismo. O bien de nada, de restos de nada. A este respecto, Derrida escribe: "Khôra es nada: el lugar de una restancia infinita, de un inmemorial desierto en el desierto, impasible, sin rostro, cualquier otro" (Derrida 200035 traducción mía) ${ }^{10}$.

Pensamos, al final, que este lugar innombrable es el espacio primitivo de toda autoridad. Un espacio que, yendo más allá del mito (pero de alguna manera exigido por él), permite intuir un innombrable que se acopla a toda autoridad posible. La autoridad, entonces, residiría originalmente en un sitio deshabitado, que no puede más que insinuarse en cada manifestación de lo sensible. Y este sitio deshabitado no podría ser más que el espacio para una fuga —o fugas — infinitas, en las que la autoridad se intuye en un ir y venir permanente, inmanente para el mundo y el tiempo; completamente desconocido.

Más allá de los mitos freudianos, de lo simbólico-real lacaniano o de la mitología blanca derridiana, la autoridad se disemina en una dimensión siempre inconclusa y por habitar; dimensión que siempre implicará el pasaje por el mito hacia regiones aún más indescifrables. Este sería el mito "de" la autoridad, su eterno paso hacia lo irreductible.

\section{Bibliografía}

Agüero, Javier. "A pesar de la herencia. Sobre lo pendiente entre Freud y Derrida". Nombres 28 (2014): 57-75.

Aristóteles. Poética de Aristóteles. Madrid: Editorial Gredos, 1992.

De Peretti, Cristina. "Herencias de Derrida". Isegorías 32 (2005): 119-133.

10 Esta noción de Khôra podría emparentarse en Derrida con su exégesis sobre la ceniza; ceniza entendida aquí como lo que queda de la nada, o la nada de la nada. Un resto sin testimonio que no permite el más primitivo de los recuerdos. "Tengo ahora la impresión de que el mejor paradigma de la huella no es [...] la pista de caza [...], el surco en la arena, la estela en el mar [...] sino la ceniza (lo que queda sin quedar del holocausto, lo que queda de lo que ha sido completamente quemado)" (1987b 27 trad. mía). 
Derrida, Jacques. La différance. Paris: Seuil, 1968.

Derrida, Jacques. "La mythologie blanche". Marges de la philosophie. Paris: Éditions de minuit, 1972a.

Derrida, Jacques. "Ousia et Grammé". Marges de la philosophie. Paris: Minuit, 1972b.

Derrida, Jacques. "Spéculer-sur- «Freud»". La carte postale. De Socrate à Freud et au-delà. Paris: Flammarion, 1980.

Derrida, Jacques. "La retrait de la métaphore". Psyché. Inventions de l'autre. Paris: Galilée, 1987a.

Derrida, Jacques. Feu la cendre. Paris: Des femmes, 1987b.

Derrida, Jacques. Mémoires pour Paul de Man. Paris: Galilée, 1988.

Derrida, Jacques. Khôra. Paris: Galilée, 1993.

Derrida, Jacques. Force de loi. Le Fondement mystique de l'autorité. Paris: Galilée, 1994.

Derrida, Jacques. Le monolinguisme de I'autre. Paris: Galilée, 1996.

Derrida, Jacques. Foi et savoir, suivi de Le siècle et le pardon. Paris: Éditions du Seuil, 2000.

Delueze, Gilles. Nietzsche y la filosofía. Madrid: Anagrama, 2006.

Freud, Sigmund. "Tótem y tabú". Sigmund Freud, Obras completas. Tomo XIII. Buenos Aires: Amorrortu, 1998.

Freud, Sigmund. Cartas a Wilhelm Fliess (1887-1904). Buenos Aires: Amorrortu, 1994.

Freud, Sigmund. "La novela familiar de los neuróticos". Sigmund Freud, Obras completas. Tomo IX. Buenos Aires: Amorrortu, 1992.

Homero. Odisea. Madrid: Editorial Gredos, 2002.

Lacan, Jacques. Le Séminaire. Livre IV, La relation d'objet. Paris: Seuil, 1994.

Lacan, Jacques. Le Séminaire. Livre 5, Les formations de l'inconscient. Paris: Seuil, 1957-1958.

Lacan, Jacques. El seminario. Libro 8, La transferencia. Barcelona: Paidós, 1960-1961.

Major, René. Lacan avec Derrida : analyse désistentielle. Paris: Champs Flammarion, 2001. 